\title{
Calcium and phosphate content of intravenous feeding regimens for very low birthweight infants
}

\author{
G AIKEN AND W LENNEY \\ Trevor Mann Baby Unit, Royal Sussex County Hospital, and Royal Alexandra Hospital for \\ Sick Children, Brighton
}

SUMMARY Fifteen infants with birth weights below $1500 \mathrm{~g}$, who required intravenous feeding from birth, were given one of two regimens differing only in their calcium and phosphate content. The duration of intravenous feeding varied from 26 to 75 days, and infants were studied after the age of 10 days when growth could be expected to have started. Five infants were given regimen A, which provided calcium and phosphate intakes of 0.55 and $0.44 \mathrm{mmol} / \mathrm{kg} / \mathrm{day}$, and 10 received regimen $\mathrm{B}$, which provided intakes of 1.08 and $0.89 \mathrm{mmol} / \mathrm{kg} / \mathrm{day}$, respectively.

Infants given regimen $\mathrm{A}$ had lower plasma and urine phosphate but similar urine calcium excretion to those given regimen B. Plasma calcium concentrations were higher in infants on regimen $A$ than regimen $B$. In infants given regimen $B$ plasma phosphate concentration was inversely related to weight gain, and urine phosphate and calcium concentrations were significantly correlated with urine sodium results.

Radiological abnormalities of bone mineralisation are common in very low birthweight infants. Most develop some degree of generalised bone radiolucency (osteopenia) due to reduced concentration of bone mineral, but this is difficult to quantify radiologically. A minority, however, develop rickets, characterised radiologically by fraying, cupping, and widening of the metaphysis. Almost all reported cases of rickets in preterm infants have birth weights below $1500 \mathrm{~g}$, most being below $1000 \mathrm{~g}$ where the prevalence in survivors may be $50 \% .{ }^{1}$ The diagnosis has been made as early as five weeks after birth, with most cases being evident by 15 weeks. Osteopenia and rickets are usually asymptomatic but can produce pathological fractures and may contribute to respiratory problems. ${ }^{2.3}$

The causes of osteopenia and rickets in preterm infants include vitamin $D$, phosphate, and calcium deficiency. There have been many reports of rickets in infants requiring intravenous feeding during the first few weeks, but detailed compositions of the feeding regimens are seldom provided. ${ }^{+6}$ Before this study an intravenous feeding regimen was used in Brighton with a low calcium and phosphate content. Because of concern that this regimen may have contributed to poor bone mineralisation it was decided to compare it with one containing twice the amounts of calcium and phosphate.
The infants were monitored radiologically as well as biochemically with serial plasma and urine calcium and phosphate measurements. Only the results obtained after 10 days of age, when growth could be expected to have started, are considered here. The results obtained in the first 10 days were considered to reflect biochemical transition to extrauterine life and are not reported here. ${ }^{7}$

\section{Patients and methods}

Patients. Over a six month period 34 infants with birth weights below $1500 \mathrm{~g}$ were admitted to the Trevor Mann Baby Unit in Brighton. Seven died and two were returned to their referring hospital within the first week. Of the remaining 25 infants, 20 required intermittent positive pressure ventilation for respiratory distress or apnoea. Infants requiring respiratory support were given intravenous fluids only, and intravenous feeding was started on day 3 . Fifteen were given intravenous feeding exclusively for more than 10 days, and these infants are considered in this study. The duration of the intravenous feeding varied from 26 to 75 days, and eight infants received it for more than 40 days. Intravenous feeding was given only through peripheral infusion sites, which were resited as promptly as possible. 
All infants were white, and none had congenital abnormalities. One infant was below the 10th centile for weight on Lubchenco intrauterine growth curves. $^{8}$ Two infants with the longest duration of intravenous feeding, 66 and 75 days, developed conjugated hyperbilirubinaemia with peak conjugated bilirubin concentrations of 50 and $123 \mu \mathrm{mol} / \mathrm{l}$, which was first detected on day 65 and 73 and had resolved by day 104 and 129 , respectively. One infant died on day 45 with disseminated intravascular coagulation, splenomegaly, and ascites. Bacteriological culture results were negative, and no surgical cause was found at laparotomy. No other serious complications occurred, although suspected episodes of infection, particularly with Staphylococcus epidermidis, were common. There were no cases of necrotising enterocolitis either during intravenous feeding or after the introduction of milk feeds. The surviving infants were stable, breathing spontaneously in air by day 25 in two cases, day 50 in five, and day 70 in six, but one infant required oxygen until day 119 . Nine infants were treated with theophylline, and four were given indomethacin for patent ductus arteriosus after day 10. Regular treatment with frusemide was only given to one infant from day 43 to 50 . Penicillin and gentamicin or cefuroxime were used for suspected infections.

Intravenous feeding. Intravenous feeding consisted of $10 \%$ dextrose-Vamin solution beginning on day 3 at a rate of $120 \mathrm{ml} / \mathrm{kg} /$ day and Intralipid $20 \%$ solution beginning on day 5 given at $10-15 \mathrm{ml} / \mathrm{kg} /$ day. The Intralipid $20 \%$ solution was composed of $100 \mathrm{ml}$ Intralipid $20 \%$ and $10 \mathrm{ml}$ Vitlipid Infant (both KabiVitrum Ltd), and provided a vitamin $\mathrm{D}_{2}$ intake of roughly $100 \mathrm{U} / \mathrm{kg} /$ day.

Infants requiring intravenous feeding were allocated alternately to regimen A or B, which differed only in their calcium and phosphate content, as shown in Table 1. Regimen A was used in Brighton before this study and regimen $B$ contained double the amount of calcium and phosphate. After five infants had been studied on regimen A for more than 10 days it was stopped because biochemical and clinical problems were being encountered. One infant developed frank radiological rickets while on intravenous feeding, and one developed mild radiological rickets after the period of intravenous feeding. Two further babies had plasma phosphate concentrations persistently below $1.2 \mathrm{mmol} / \mathrm{l}$ $(3.7 \mathrm{mg} / 100 \mathrm{ml})$ after the period of feeding, and these required phosphate supplementation. All subsequent infants requiring intravenous feeding were allocated to regimen $\mathrm{B}$, which was given to 10 infants for more than 10 days.

Ten $\mathrm{ml}$ of Intralipid $20 \%$ provides $0.15 \mathrm{mmol}$ phosphate (data obtained from KabiVitrum Ltd). This may not be utilised as readily as the phosphate from dextrose-Vamin solution and has therefore not been included in our calculations.

Measurements. Venous or arterial samples for plasma calcium and phosphate concentrations and untimed urine samples for calcium, phosphate,

Table 1 Composition of $10 \%$ dextrose-Vamin solution used in regimen $A$ and regimen $B$

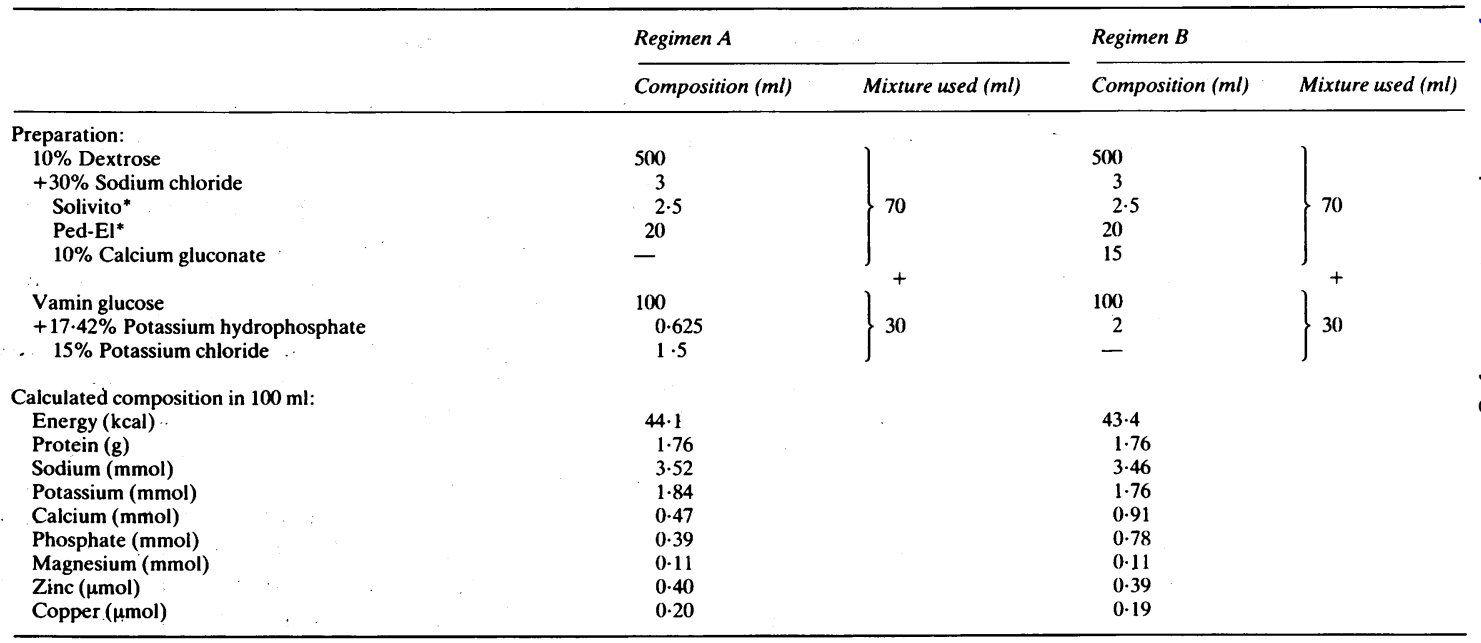

*Manufactured by KabiVitrum Ltd. 
Table 2 Comparison of infants given intravenous feeding regimen $A(n=5)$ and regimen $B(n=10)$ from 11-30 days

\begin{tabular}{|c|c|c|c|c|c|c|}
\hline & \multicolumn{3}{|c|}{ Regimen $A$} & \multicolumn{3}{|c|}{ Regimen $B$} \\
\hline & Mean & $(S D)$ & Range & Mean & $(S D)$ & Range \\
\hline Birth weight $(g)$ & 1067 & (239) & $738-1.370$ & 1066 & (198) & $756-1342$ \\
\hline Gestational age (weeks) & $28 \cdot 0$ & $(1 \cdot 0)$ & $27-29$ & 27.9 & $(1.2)$ & $26-30$ \\
\hline Energy intake ( $\mathrm{kcal} / \mathrm{kg} /$ day $)$ & $70 \cdot 4$ & $(8 \cdot 6)$ & $56-78$ & $70 \cdot 3$ & $(5 \cdot 2)$ & $58-76$ \\
\hline Weight gain ( $g / \mathrm{kg} /$ day $)$ & $11 \cdot 3$ & $(3 \cdot 0)$ & $7 \cdot(0-14 \cdot 2$ & 13.0 & $(1.7)$ & $10 \cdot 3-15 \cdot 6$ \\
\hline Calcium intake $(\mathrm{mmol} / \mathrm{kg} /$ day $)$ & 0.55 & (0.05) & $(0.50-0.63$ & $1 \cdot 08$ & (0.01) & $0.99-1.22$ \\
\hline Phosphate intake $(\mathrm{mmol} / \mathrm{kg} / \text { day })^{*}$ & 0.44 & $(0.03)$ & $(0.41-0.48$ & 0.89 & $(0.06)$ & $0.78-1.98$ \\
\hline
\end{tabular}

*The phosphate intake in Intralipid has not been included.

sodium, and creatinine concentrations were obtained at twice weekly intervals from each patient during the period of intravenous feeding (plasma calcium measurements were made more frequently). Plasma calcium concentration was measured using methyl thymol blue, urine calcium concentration by the o-cresolphthalein complexone method, plasma phosphate concentration by the Fiske-Subbarow method, urine phosphate concentration by an acid molybdate hydroquinone ascorbate reductase technique, urine sodium concentration by flame photometry, and urine creatinine concentration by the Jaffé reaction. Manual ultra microprocedures were used on all plasma samples, and urine calcium and phosphate assays were performed on the Vickers M300 analyser.

Radiographs of the left wrist were taken at fortnightly intervals until discharge from hospital. All $x$ ray films were reviewed by a paediatric radiologist. Fluid intake was accurately recorded and body weight was measured using the same electronic scale.

Analysis. Urine calcium, phosphate, and sodium results were expressed as creatinine ratios. The results were divided into groups according to the age intervals 11-20 days, 21-30 days, and 31-40 days and were analysed using two sample $t$ tests and correlation coefficients. Changes with postnatal age were assessed by comparing the results from 21-30 days and 31-40 days with those from 11-20 days. When comparing the results from 31-40 days with 11-20 days the results from infants who were given intravenous feeding for less than 30 days were excluded. Insufficient results were obtained after 40 days to allow satisfactory analysis.

\section{Results}

Comparison of intravenous feeding regimens $A$ and B. As shown in Table 2 from 11-30 days the mean birth weight, gestational age, energy intake, and weight gain of infants given regimen $\mathrm{A}$ or $\mathrm{B}$ were comparable. Infants on regimen $B$ received twice the amount of calcium and phosphate.

The plasma calcium and phosphate results are shown in Figure 1 and the urine calcium, phosphate, and sodium results in Figure 2. Mean plasma calcium concentration on regimen $\mathrm{A}$ was significantly higher than on regimen $B$ at 11-20 days and 21-30 days, but then fell significantly $(p<0 \cdot 01)$ to a concentration comparable with regimen $B$ at $31-40$

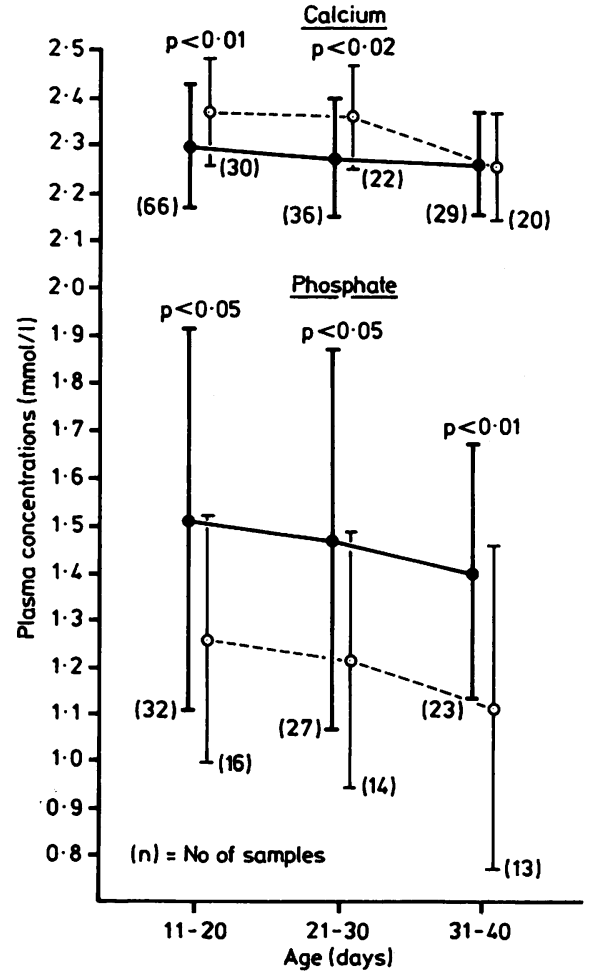

Fig. 1 Plasma calcium and phosphate concentrations in infants given intravenous feeding regimen $A\left(-\right.$ - $\left._{-}\right)$and regimen $B(-)$. Values are mean $(S D)$. 


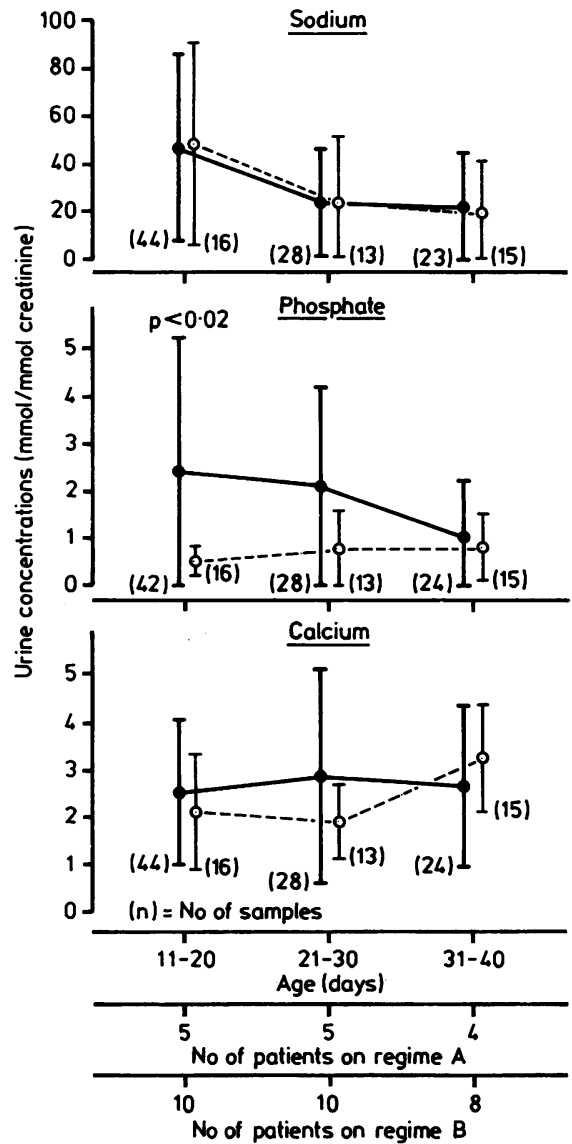

Fig. 2 Urine calcium, phosphate, and sodium concentrations (mmol/mmol creatinine) in infants given intravenous feeding regimen $A(---)$ and regimen $B$ $(\longrightarrow)$. Values are mean $(S D)$.

days. The mean plasma phosphate concentration was significantly lower on regimen $A$ than on regimen $B$ at all age intervals, and no significant changes with postnatal age occurred. No significant differences in urine calcium concentration were found between the two regimens. Mean urine calcium concentration on regimen A was significantly higher at 31-40 days than at 11-20 days $(p<0 \cdot 05)$. Mean urine phosphate concentration on regimen $B$ was significantly higher than on regimen $A$ at $11-20$ days but then fell significantly $(p<0.02)$ to a concentration comparable with regimen $\mathrm{A}$ at 31-40 days. Mean urine sodium concentration on regimen $\mathrm{A}$ and regimen $\mathrm{B}$ was comparable and fell significantly from 11-20 days to 21-30 days $(\mathrm{p}<0 \cdot 01)$.
Plasma phosphate concentration on intravenous feeding regimen $\mathbf{B}$. In individual infants receiving regimen $\mathrm{B}$ the mean plasma phosphate concentration from 11-30 days varied from 1.12 to $2.01 \mathrm{mmol} / \mathrm{l}$ $(3.47-6.22 \mathrm{mg} / 100 \mathrm{ml})$. No association between mean plasma phosphate concentration and birth weight, gestational age, or phosphate intake was found. As shown in Figures 3-5, however, the mean plasma phosphate concentration was significantly correlated with weight gain and plasma calcium concentration but not with urine phosphate concentration. (Neither was there a significant correlation with urine calcium concentration).

Relation between urine sodium, phosphate, and calcium concentrations on intravenous feeding regimen B. Analysis of all the urine results from 11-30 days of infants given intravenous feeding regimen $B$

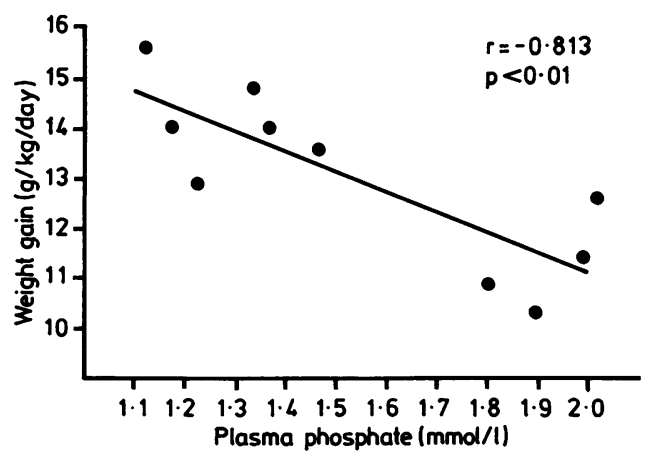

Fig. 3 The relation between mean plasma phosphate concentration and weight gain in infants given intravenous feeding regimen $B$ from day $11-30$.

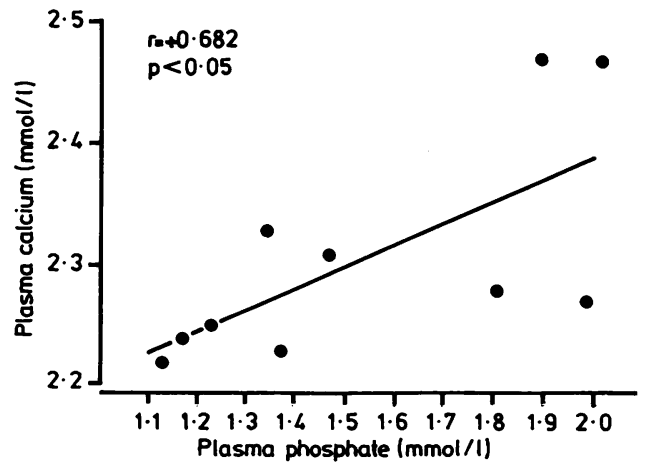

Fig. 4 The relation between mean plasma phosphate concentration and mean plasma calcium concentration in infants given intravenous feeding regimen $B$ from day 11-30. 
showed a significant correlation between urine sodium and urine phosphate concentrations $(r=$ $+0 \cdot 62, \mathrm{n}=70, \mathrm{p}<0 \cdot 001)$ and urine sodium and urine calcium concentrations $(\mathrm{r}=+0 \cdot 54, \mathrm{n}=72, \mathrm{p}<0 \cdot 001)$, all expressed as $\mathrm{mmol} / \mathrm{mmol}$ creatinine.

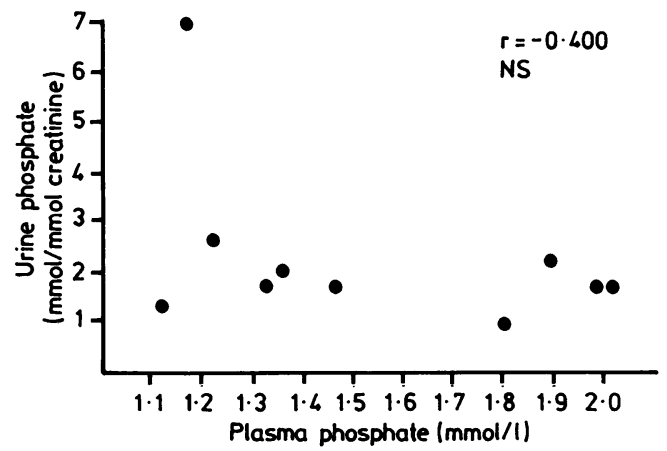

Fig. 5 The relation between mean plasma phosphate concentration and mean urine phosphate concentration in infants given intravenous feeding regimen $B$ from day $11-30$.
Radiological abnormalities. The diagnosis of rickets depends on the radiological finding of an irregular frayed metaphysis with widening and cupping. Osteoporosis alone was not considered to indicate rickets. Of the 14 surviving infants, radiological rickets developed in four during their hospital admission, two of whom were being given regimen $A$ and two regimen $B$. In three infants only the ulnar metaphysis was affected and the diagnosis was made after the period of intravenous feeding. In the remaining infant who was given regimen $\mathrm{A}$ florid rickets with rib fractures developed during the period of intravenous feeding and was first diagnosed on day 39 .

\section{Discussion}

There are no reports of calcium and phosphate balance studies in intravenously fed low birthweight infants after the age of 10 days. A number of studies have been performed, however, in infants fed on breast or various formulas milks. In these studies the

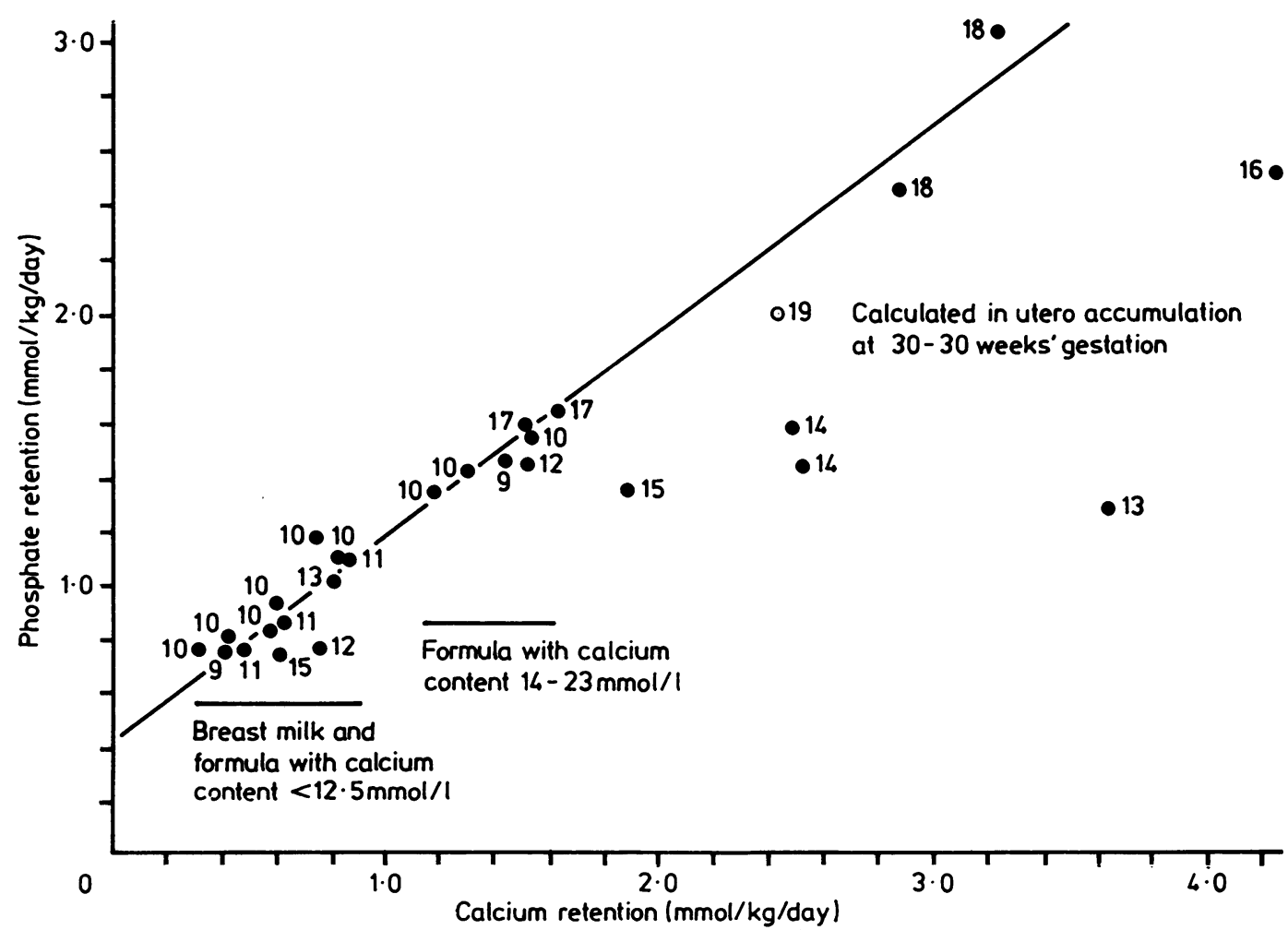

Fig. 6 Summary of calcium and phosphate retention data from balance studies performed in very low birthweight babies given various milk feeds. The numbers relate to references in the text. 
infants have had birth weights varying from less than $1200 \mathrm{~g}^{9}$ to more than $1600 \mathrm{~g}^{10-19}$ and were studied in general at the age of 3-4 weeks when their growth rates equalled or exceeded that expected in utero. A summary of the results is given in Figure 6. Most studies show a close relation between the rates of calcium and phosphate retention in keeping with the requirement of phosphate for soft tissue growth and the molar calcium to phosphate ratio in bone of about 10:6.

In an attempt to overcome the difficulty of timed urine collections untimed samples were obtained in this study and the concentrations of calcium, phosphate, and sodium were expressed as creatinine ratios. In a group of intravenously fed low birthweight infants aged 5-14 days urine creatinine excretion was found to be a relatively constant function of body weight independent of postnatal age, with values increasing slightly from 0.070 $\mathrm{mmol} / \mathrm{kg} /$ day at a birth weight of $1000 \mathrm{~g}$ to 0.075 $\mathrm{mmol} / \mathrm{kg} /$ day at $1600 \mathrm{~g} .{ }^{20}$ The urine concentration of a substance per mmol of creatinine should therefore be directly related to the urine excretion of that substance per unit body weight. This allows comparison of the urine excretion of a substance between groups of infants to be made by measuring creatinine ratios in untimed urine samples.

In this study two intravenous feeding regimens differing only in their calcium and phosphate contents were compared. Regimen A provided calcium and phosphate intakes of 0.55 and $0.44 \mathrm{mmol} / \mathrm{kg} /$ day, respectively. The results in Figure 6 suggest that at a growth rate similar to that in utero this regimen should only provide sufficient phosphate for soft tissue growth, making the calcium unavailable for bone mineralisation. Infants given this regimen had low plasma and urine phosphate results and similar urine calcium excretion to those given regimen $B$, which provided twice the calcium intake. In addition, urine calcium excretion increased with postnatal age, and up to the age of 30 days plasma calcium concentration was higher in infants on regimen $A$ than in infants on regimen $B$. One infant who had the fastest growth rate in the group given regimen $\mathrm{A}(14.2 \mathrm{~g} / \mathrm{kg} /$ day $)$ developed rickets while on intravenous feeding first detected on day 39. Reported cases of rickets in preterm infants fed on breast milk who responded to treatment with phosphate supplements have had plasma phosphate concentrations below $1.2 \mathrm{mmol} / \mathrm{l}(3.7 \mathrm{mg} /$ $100 \mathrm{ml}$ ), with low urine phosphate and high urine calcium excretion, and in some cases plasma calcium concentrations above $2.5 \mathrm{mmol} / \mathrm{l}^{21-24}$ These biochemical findings are similar to those found in infants given regimen $\mathrm{A}$ and suggest the development of phosphate deficiency. It would seem, therefore, that regimen A provides insufficient phosphate for use in very low birthweight infants.

Regimen B provided calcium and phosphate intakes of 1.08 and $0.89 \mathrm{mmol} / \mathrm{kg} /$ day, respectively. On this regimen plasma phosphate concentration was inversely related to weight gain. Plasma phosphate concentrations were below $1.5 \mathrm{mmol} / \mathrm{l}(4.6$ $\mathrm{mg} / 100 \mathrm{ml}$ ) at rates of weight gain similar to those in utero, suggesting the development of phosphate deficiency. In a recent case report an infant weighing $890 \mathrm{~g}$ at birth developed rickets while on a comparable intravenous feeding regimen and had the typical biochemical features of phosphate deficiency. ${ }^{6}$ In our study, however, phosphate deficiency may not be the only explanation for the inverse relation between plasma phosphate concentration and weight gain because lower plasma phosphate concentrations were not associated with either a fall in urine phosphate or an increase in urine calcium excretion. They were associated, however, with lower plasma calcium concentrations, instead of the higher concentrations expected in phosphate deficiency. Calcium and phosphate retention on regimen B may be limited by a number of factors, which are as follows.

Inappropriate calcium:phosphate ratio. Based on calculated in utero retention rates, ${ }^{19}$ an appropriated molar calcium to phosphate ratio in intravenous feeding regimens would be $1 \cdot 2$ : 1 equivalent to that in regimen $B$. Figure 6 indicates, however, that at a calcium intake of $1.2 \mathrm{mmol} / \mathrm{kg} /$ day a phosphate intake of $1.3-1.4 \mathrm{mmol} / \mathrm{kg} / \mathrm{day}$ would be more appropriate, provided the growth rate is similar to that in utero. At slower growth rates less phosphate would be required for soft tissue growth.

Renal immaturity. As expected from previous studies $^{25}$ urine sodium excretion decreased with increasing postnatal age, and a similar fall in urine phosphate excretion occurred in infants given regimen $B$. In these infants a significant association was found between urine sodium and phosphate concentrations as well as between urine sodium and calcium concentrations, but urine calcium excretion did not fall with increasing postnatal age. These results suggest that a major factor limiting calcium and phosphate retention from intravenous feeding in immature infants may be renal tubular wasting of these ions, particularly phosphate, in association with sodium wasting.

Deficiency of magnesium and trace elements. Although the magnesium content of regimen B was low, the magnesium intake was similar to the 
retention rate found by Day et al. ${ }^{13}$ The zinc and copper intakes, however, were considerably below the estimated in utero retention rates, ${ }^{26}$ but their role in calcium and phosphate metabolism is unclear.

Vitamin D deficiency. This possibility has not been investigated in comparable infants given intravenous feeding.

\section{Conclusion}

These factors need further investigation to enable the formulation of intravenous feeding regimens that will promote optimal calcium and phosphate retention in very low birthweight babies and prevent the development of osteopenia and rickets.

We thank the nursing staff on the Trevor Mann Baby Unit and the Biochemistry and the Medical Photographic Departments, Royal Sussex County Hospital, for their help, Miss N Winser for secretarial help, and Dr Neil McIntosh and Professor David Hull for their comments. We are grateful to the Royal Alexandra Hospital Centenary Fund for financial support.

\section{References}

1 McIntosh N, Livesey A. Brooke OG. Plasma 25 hydroxyvitamin $\mathrm{D}$ and rickets in infants of extremely low birth weight. Arch Dis Child 1982:57:848-50.

2 Geggel RL. Pereira GR. Spackman TJ. Fractured ribs: unusual presentation of rickets in premature infants. $J$ Pediatr 1978:93:680-2.

${ }^{3}$ Glasgow JFT, Thomas PS. Rachitic respiratory distress in small premature infants. Arch Dis Child 1977;52:268-74.

+ Leape LL. Valaes T. Rickets in low birth weight infants receiving total parenteral nutrition. J Pediatr Surg 1976;11: 665-74.

5 Binstadt DH, L'Heurcux PR. Rickets as a complication of intravenous hyperalimentation in infants. Pediatr Radiol 1978:7:211-4.

" The TS, Kollee LAA, Boon JM. Monnens LAH. Rickets in a preterm infant during intravenous alimentation. Acta Paediatr Scand 1983:72:769-71.

7 Aiken G, Lenney W. Urine calcium and phosphate excretion in very low birth weight infants during the first 10 days. (Unpublished findings.)

" Lubchenco LO, Hansman C. Dressler M, Boyd E. Intrauterine growth as estimated from live born birth weight data at 24 to 42 wecks of gestation. Pediatrics 1963;32:793-800.

"Lyon AJ. McIntosh N. Calcium and phosphorus balance in extremely low birthweight infants in the first six weeks of life. Arch Dis Child 1984:59:1145-50.
11) Senterre J, Salle B. Calcium and phosphorus economy of the preterm infant and its interaction with vitamin $D$ and its metabolites. Acta Paediatr Scand [Suppl] 1982;296:85-92.

"Senterre J, Putet G, Salle B, Rigo J. Effects of vitamin D and phosphorus supplementation on calcium retention in preterm infants fed banked human milk. J Pediatr 1983;103:305-7.

12 Rowe J, Rowe D, Horak E, et al. Hypophosphatemia and hypercalciuria in small preterm infants fed human milk: cvidence for inadequate dietary phosphorus. J Pediatr 1984; 104:112-7.

1.3 Day GM, Chance GW, Radde IC, Reilly BJ, Park E, Sheepers $J$. Growth and mineral metabolism in very low birth weight infants. II. Effects of calcium supplementation on growth and divalent cations. Pediatr Res 1975;9:568-75.

14 Cifuentes RF, Radde IC, Chance GW, Martin DJ, Jones G. Effects of two oral doses of vitamin D3 in very low birth weight infants. Pediatr Res 1979;13:397.

15 Atkinson SA, Radde IC, Anderson GH. Macromineral balances in premature infants fed thcir own mothers milk or formula. J Pediatr 1983;102:99-106.

16 Shenai JP, Reynolds JW, Babson SG. Nutritional balance studies in very low birth weight infants: enhanced nutrient retention rates by an experimental formula. Pediatrics 1980; 66:233-8

17 Shenai JP, Jhaveri BM, Reynolds JW, Huston RK, Babson SG. Nutritional balance studies in very low birth weight infants: role of soy formula. Pediatrics 1981;67:631-7.

18 Huston RK, Reynolds JW, Jensen C, Buist NRM. Nutrient and mineral retention and vitamin $D$ absorption in low birth weight infants: effects on medium-chain triglycerides. Pediatrics 1983;72:44-8.

19 Ziegler EE, O'Donnell AM, Nelson SE, Fomon SJ. Body composition of the reference fetus. Growth 1976;40:329-41.

20) Sutphen JL. Anthropometric determinants of creatinine excretion in preterm infants. Pediatrics 1982;69:719-23.

21 Rowe JC, Wood DH, Rowe DW, Raisz LG. Nutritional hypophosphatemic rickets in a premature infant fed breast milk. $N$ Engl J Med 1979;300:293-6.

22 Sagy M, Birenbaum E, Balin A, Orda S, Barzilay Z, Brish M. Phosphate depletion syndrome in a premature infant fed human milk. J Pediatr 1980;96:683-5.

${ }_{2.3}$ Greer FR, Steichen JJ, Tsang RC. Calcium and phosphate supplements in breast milk related rickets. Am J Dis Child 1982;136:581-3.

${ }^{24}$ Koo WWK, Antony G, Stevens LHS. Continuous nasogastric phosphorus infusion in hypophosphatemic rickets of prematurity. Am J Dis Child 1984:138:172-5.

25 Al-Dahhan J, Haycock GB, Chantler C, Stimmler L. Sodium homeostasis in term and preterm neonates. 1. Renal aspects. Arch Dis Child 1983;58:335-42.

${ }^{26}$ Shaw JCL. Parenteral nutrition in the management of sick low birth weight infants. Pediatr Clin North Am 1973;20:333-43.

Correspondence to Dr G Aiken, Trevor Mann Baby Unit, Royal Sussex County Hospital, Brighton, England.

Received 10 January 1986 